Jurnal Inkofar * Volume 1 No. 1, Juli 2017 * ISSN: 2615-3645 (Print) / 2581-2920 (Online)

Tersedia secara online di: http://www.politeknikmeta.ac.id/meta/ojs/

\title{
PERANCANGAN APLIKASI SISTEM PAKAR DENGAN MENGGUNAKAN METODE CERTAINTY FACTOR UNTUK MENENTUKAN JENIS GANGGUAN DISLEKSIA BERBASIS WEB
}

\author{
Fakhrul Rahman', Eka Praja Wiyata mandala, M. Kom ${ }^{2)}$, Teri Ade Putra, M. Kom ${ }^{3)}$ \\ Teknik Informatika, Universitas Putra Indonesia "YPTK", Padang \\ Email : fakhrulrahman0411@gmail.com \\ Teknik Informatika, Universitas Putra Indonesia "YPTK", Padang \\ Email : ekaprajawm@upiyptk.ac.id \\ Teknik Informatika, Universitas Putra Indonesia "YPTK”, Padang \\ Email : teriputra2@gmail.com
}

\begin{abstract}
Dyslexia is a learning difficulty that is best known. Lack of parental supervision to diagnose early reading skills of children caused by factors parents who are too busy and less know the normal development of children. Their services in the form of web-based expert system aims to determine the type of disorder dyslexia as well as to facilitate parents in early diagnosing dyslexia types of disorders experienced by children. The method used to make the application of expert systems is the method of Certainty Factor $(\mathrm{CF})$ is a method to verify whether or not the fact it was definitely uncertain. It is hoped this method will produce an expert system with a degree of certainty that is accurate and suitable to determine something that is uncertain.
\end{abstract}

Keywords: Expert System, Certainty Factor, Dyslexia

\section{PENDAHULUAN}

Perkembangan teknologi informasi dan komunikasi di zaman modern ini mendorong masyarakat untuk menciptakan suatu terobosan baru meggunakan sistem yang lebih praktis serta pelayanannya yang lebih cepat dengan hasil yang akurat. Akibat kurangnya informasi tentang gejala-gejala suatu penyakit, banyak orang yang tidak mengetahui jenis penyakit apa yang sedang dideritanya. Menurut Cronbach (dalam Djamarah, 2002) mendefinisikan belajar sebagai suatu aktivitas yang ditunjukkan oleh perubahan tingkah laku sebagai hasil dari pengalaman (Kawuryan Fajar \& Raharjo Trubus: 2012).

Disleksia (dyslexia) adalah sebuah gangguan dalam perkembangan baca-tulis yang umumnya terjadi pada anak menginjak usia 7 hingga 8 tahun. Ditandai dengan kesulitan belajar membaca dengan lancar dan kesulitan dalam memahami meskipun normal atau diatas rata-rata. Diseleksia adalah kesulitan belajar yang paling umum dan gangguan membaca yang paling dikenal. Permasalahan lain yang ditemukan pada anak dengan gangguan disleksia ini adalah kurangnya perhatian orang tua untuk mendiagnosa dini kemampuan membaca anak. Hal ini disebabkan karena faktor orang tua yang terlalu sibuk atau yang kurang mengetahui perkembangan anak secara normal. Oleh sebab itu muncul pelayanan berbasis web untuk menentukan jenis disleksia dengan tujuan untuk mempermudah orang tua dalam mendiagnosa dini jenis disleksia yang dialami anak. Metode yang digunakan untuk membuat aplikasi sistem pakar adalah metode Certainty Factor (CF) yang merupakan suatu metode untuk membuktikan apakah suatu fakta itu pasti ataukah tidak pasti. Metode ini sangat cocok untuk sistem pakar yang mendiagnosis sesuatu yang sifatnya belum pasti.

\subsection{Rekayasa Perangkat Lunak}

Rekayasa perangkat lunak (Software Engineering) merupakan pembangunan dengan menggunakan prinsip atau konsep rekayasa dengan tujuan menghasilkan perangkat lunak yang bernilai ekonomi yang dipercaya dan bekerja secara efisien menggunakan mesin (Rosa dan Salahuddin,2013).

\subsection{Unified Modeling Language (UML)}

Salah satu pemodelan yang saat ini paling banyak digunakan adalah UML. Unified Modeling Language (UML) adalah salah satu standar bahasa yang banyak digunakan di dunia industri untuk mendefenisikan requirement, membuat analisis dan desain, serta menggambarkan arsitektur dalam pemrograman berorientasi objek. Pada UML, terdiri dari empat belas macam diagram yang 
dikelompokkan dalam tiga kategori. Pembagian kategori dan macam-macam diagram tersebut dapat dilihat pada gambar dibawah ini (Rosa dan Salahuddin, 2013).

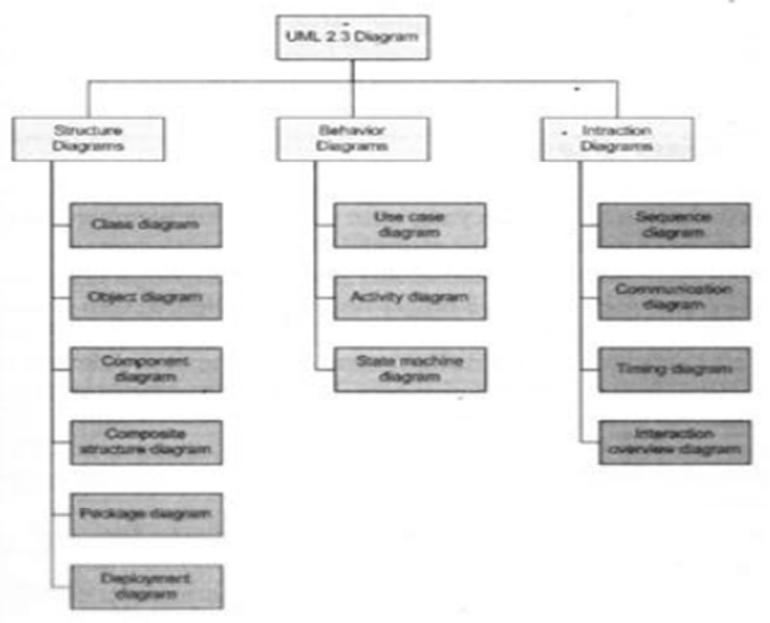

Gambar 1. Diagram UML (Rosa dan Salahuddin,2013)

\subsection{Kecerdasan Buatan (Artificial Intelligence)}

Artificial Intelligence (AI) atau kecerdasan buatan merupakan cabang dari ilmu komputer yang menaruh perhatian pada pengotomatisasi tingkah laku cerdas. Pernyataan tersebut juga dapat dijadikan defenisi dari AI. Defenisi ini menunjukkan bahwa AI adalah bagian dari komputer sehingga harus didasarkan pada sound theoretical (teori suara) dan prinsip - prinsip aplikasi dari bidangnya.

\subsection{Sistem Pakar (Expert System)}

Istilah sistem pakar berasal dari kata knowledge-based expert system. Istilah ini muncul karena untuk memecahkan suatu masalah, sistem pakar menggunakan pengetahuan yang dimasukkan ke dalam komputer. Seseorang yang bukan pakar menggunakan sistem pakar untuk meningkatkan kemampuan pemecahan masalah, sedangkan seorang pakar menggunakan sistem pakar untuk knowledge assistant.

\subsubsection{Manfaat Sistem Pakar}

Sistem pakar menjadi populer karena sangat banyak manfaat yang diberikannya, antara lain (Sutojo, dkk: 2011):

a. Meningkatkan produktivitas, karena sistem pakar dapat bekerja lebih cepat dari pada manusia.

b. Membuat seseorang yang awam bekerja layaknya seorang pakar.

c. Meningkatkan kualitas, dengan memberi nasehat yang konsisten dan mengurangi kesalahan.

d. Dapat dihandalkan, sebab sistem pakar tidak pernah merasa bosan, kelelahan, ataupun sakit.

\subsubsection{Kekurangan Sistem Pakar}

Selain manfaat, sistem pakar juga memiliki kekurangan. Diantara kekurangan sistem pakar tersebut adalah sebagai berikut (Sutojo,dkk:2011):

a. Biaya yang dibutuhkan sangat mahal untuk membuat dan memeliharanya

b. Sulit dikembangkan, karena keterbatasan keahlian dan ketersediaan pakar

c. Tidak selalu bernilai benar

\subsection{Certainty Factor}

Teori Certainty Factor (CF) mengakomodasi ketidakpastian pemikiran (inexact reasoning) seorang pakar. Seorang pakar (misalnya dokter) seringkali menganalisis informasi yang ada dengan ungkapan seperti "mungkin", "kemungkinanp besar", "hampir pasti”. Untuk mengakomodasi hal 
ini kita menggunakan certainty factor (CF) guna menggambarkan tingkat keyakinan pakar terhadap masalah yang sedang dihadapi (Sutojo, dkk, 2011). Metode 'Net belief' yang diusulkan oleh E.H. Shortliffe dan B.G.Buchanan.

$$
\begin{gathered}
\mathrm{CF} \text { (rule) }=\operatorname{MB}(\mathrm{H}, \mathrm{E})-\mathrm{MD}(\mathrm{H}, \mathrm{E}) \\
\operatorname{MB}(H, E)\left\{\begin{array}{c}
P(H)=1 \\
\operatorname{Max}[P(H \mid E), P(H)]-P(H) \\
\operatorname{Max}[1,0]-P(H)
\end{array}\right. \\
M B(H, E)\left\{\begin{array}{c}
1 \\
\operatorname{Min}[P(H)=0 \\
\operatorname{Max}[1,0]-P(H)]-P(H)
\end{array}\right.
\end{gathered}
$$

Dimana :

$\mathrm{CF}($ Rule $) \quad$ : Faktor kepastian

MB (H,E) : Measure Of Belief (Ukuran kepercayaan) terhadap hipotesis H, jika diberikan evidence $\mathrm{E}$ (antara 0 dan 1$)$.

MD (H.E) : Measure Of Disbelief (Ukuran ketidakpercayaan) terhadap evidence H, jika diberikan evidence E (antara 0 dan 1).

$\mathrm{P}(\mathrm{H}) \quad$ : Probabilitas kebenaran hipotesis $\mathrm{H}$

$\mathrm{P}(\mathrm{H} \mid \mathrm{E}) \quad$ : Probabilitas bahwa $\mathrm{H}$ benar karena faktor E.

\subsection{Sekilas Tentang Disleksia (Dyslexia)}

Disleksia (Dyslexia) merupakan gangguan kognitif yang berupa ketidak- mampuan membaca pada anak, anak kesulitan mengenal huruf-huruf yang hampir sama, dimata anak tulisan merupakan coretan yang sulit untuk dibaca. Anak dengan gangguan ini dimungkinkan mempunyai IQ yang baik, dan kemampuan lain juga baik namun dalam hal membaca akan mengalami kesulitan (Kawuryan Fajar \& Raharo Trubus, 2012).

\begin{tabular}{|c|c|c|c|}
\hline No & Kode Gangguan & Nama Gangguan & Keterangan \\
\hline 1 & P001 & $\begin{array}{l}\text { Disleksia Visual atau } \\
\text { Penglihatan }\end{array}$ & $\begin{array}{l}\text { Disleksia Visual } \\
\text { merupakan jenis } \\
\text { disleksia dimana } \\
\text { penderitanya dapat } \\
\text { melihat dengan baik } \\
\text { tetapi tidak dapat } \\
\text { membedakan } \\
\text { interpretasi, } \\
\text { mengingat perkataan, } \\
\text { nomor, bentuk } \\
\text { gambar, dan angka } \\
\text { yang dilihat. }\end{array}$ \\
\hline 2 & P002 & $\begin{array}{l}\text { Disleksia Auditoris } \\
\text { atau Pendengaran }\end{array}$ & $\begin{array}{l}\text { Disleksia Auditoris } \\
\text { atau pendengaran } \\
\text { merupakan jenis } \\
\text { disleksia dimana } \\
\text { penderitanya tidak } \\
\text { dapat membedakan } \\
\text { bunyi, dan mengenal } \\
\text { pasti bunyi didalam }\end{array}$ \\
\hline
\end{tabular}

\section{METODE PENELITIAN}

Tabel 1. Gangguan Disleksia 
Jurnal Inkofar * Volume 1 No. 1, Juli 2017 * ISSN: 2615-3645 (Print) / 2581-2920 (Online)

Tersedia secara online di: http://www.politeknikmeta.ac.id/meta/ojs/

\begin{tabular}{|l|l|l|}
\hline & & perkataan serta \\
& & mengkombinasikan \\
bunyi untuk dijadikan \\
perkataan atau \\
membagi kata dalam \\
suku kalimat.
\end{tabular}

Tabel 2. Gejala Diseleksia

\begin{tabular}{|c|c|c|c|}
\hline No & $\begin{array}{c}\text { Jenis } \\
\text { Disleksia }\end{array}$ & ID Gejala & Gejala \\
\hline \multirow[t]{6}{*}{1} & \multirow{6}{*}{$\begin{array}{l}\text { Disleksia } \\
\text { Visual atau } \\
\text { Penglihatan }\end{array}$} & G001 & $\begin{array}{l}\text { Tidak dapat membedakan perkataan atau huruf yang } \\
\text { hampir sama misalnya (bas - pas, ubi - ibu) }\end{array}$ \\
\hline & & G002 & Lambatnya proses pengamatan \\
\hline & & G003 & Sering menyebut kata terbalik misalnya (sapu -supa) \\
\hline & & G004 & Tulisan penderita yang buruk (sulit dibaca) \\
\hline & & G005 & $\begin{array}{l}\text { Daya tangkap di dalam auditory (pendengaran) sangat } \\
\text { tinggi }\end{array}$ \\
\hline & & G006 & Tidak memiliki minat dalam kegiatan olahraga \\
\hline \multirow[t]{5}{*}{2} & \multirow[t]{5}{*}{$\begin{array}{l}\text { Disleksia } \\
\text { Auditoris atau } \\
\text { Pendengaran }\end{array}$} & G007 & $\begin{array}{l}\text { Tidak dapat melakukan pengamatan dan perbedaan bunyi } \\
\text { auditory yang menyebabkan penderita sulit belajar } \\
\text { tentang kaidah bahasa }\end{array}$ \\
\hline & & G008 & Tidak dapat membagi antara perkataan dan suku kata \\
\hline & & G009 & $\begin{array}{l}\text { Tidak dapat mengungkapkan/ mengingat huruf dalam } \\
\text { kalimat }\end{array}$ \\
\hline & & G010 & Sulit memahami bunyi secara berurutan \\
\hline & & G011 & $\begin{array}{l}\text { Lebih cendrung memilih aktivitas yang memerlukan } \\
\text { kemahiran visual }\end{array}$ \\
\hline
\end{tabular}

\section{HASIL DAN PEMBAHASAN}

Berikut merupakan tampilan dari sistem pakar dileksia.

\subsection{Halaman Login}

Merupakan halaman yang digunakan oleh user untuk masuk ke account user setelah sebelumnya user melakukan registrasi.

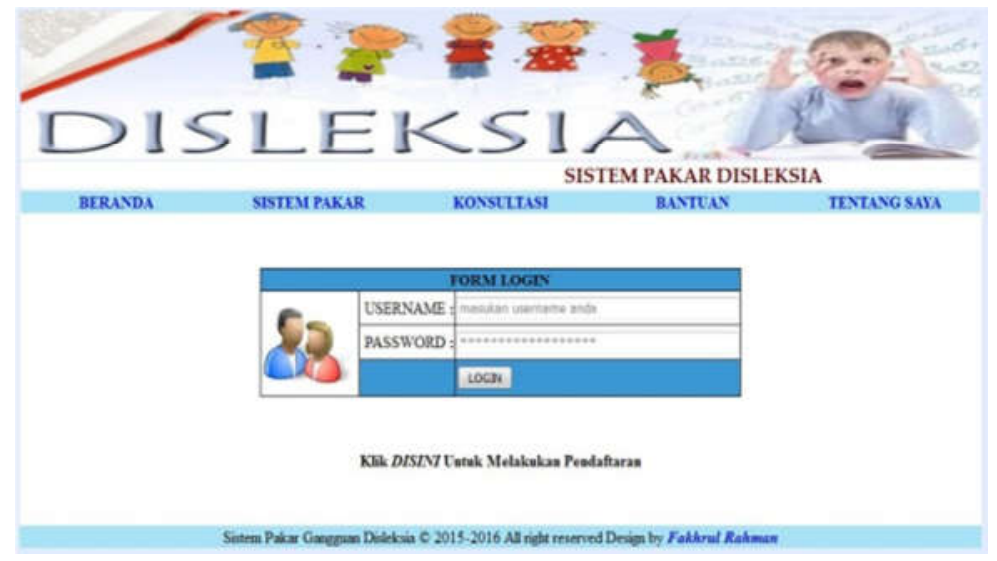

Gambar 2. Halaman Login Sistem Pakar 
Jurnal Inkofar * Volume 1 No. 1, Juli 2017 * ISSN: 2615-3645 (Print) / 2581-2920 (Online)

Tersedia secara online di: http://www.politeknikmeta.ac.id/meta/ojs/

3.2 Halaman Konsultasi

Merupakan halaman yang digunakan oleh user untuk melakukan konsultasi.

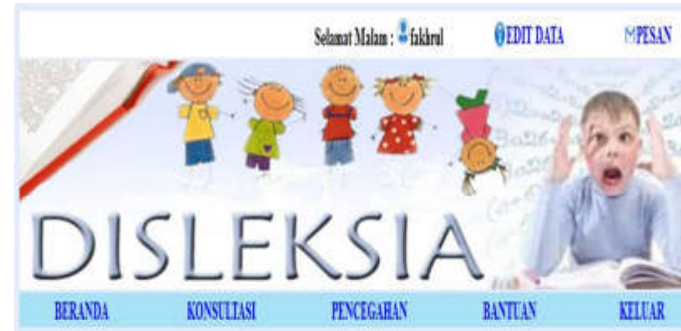

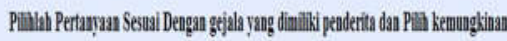

\begin{tabular}{|c|c|c|}
\hline $\mathrm{N}_{0}$ & Petargaa & 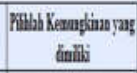 \\
\hline$!$ & 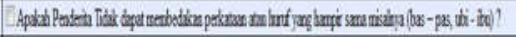 & 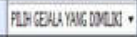 \\
\hline ? & 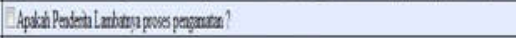 & PASELUYAG DYOSR, \\
\hline 3 & 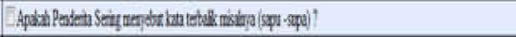 & 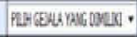 \\
\hline 4 & 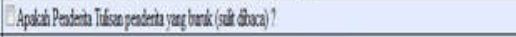 & 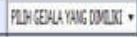 \\
\hline 3 & 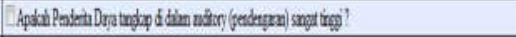 & 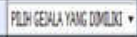 \\
\hline 6 & 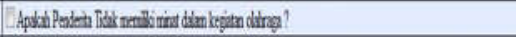 & 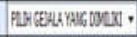 \\
\hline , & 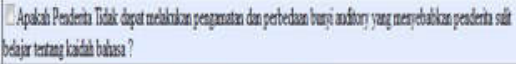 & PLA GELANG DOTAN, \\
\hline 8 & 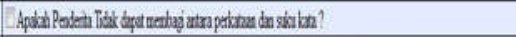 & 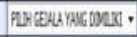 \\
\hline 9 & 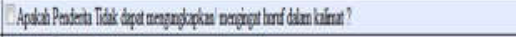 & PESTELYANGDCR, \\
\hline 10 & 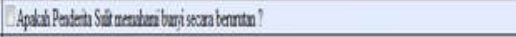 & 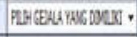 \\
\hline II & 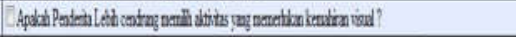 & 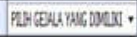 \\
\hline
\end{tabular}

Gambar 3. Halaman Konsultasi User

3.3 Halaman Hasil Konsultasi

Merupakan halaman untuk melihat hasil konsultasi yang telah didapatkan berdasarkan rule dari certainty factor.

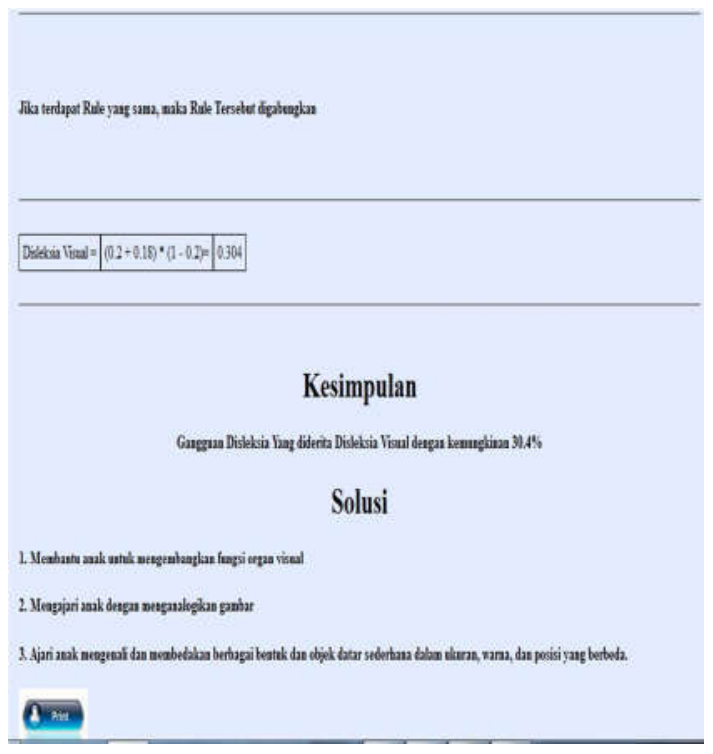

Gambar 4. Halaman Hasil Konsultasi User 


\section{KESIMPULAN}

Berdasarkan hasil analisa, perancangan dan penerapan aplikasi sistem pakar disleksia maka dapat diambil kesimpulan, yaitu:

1. Aplikasi sistem pakar ini mampu membantu orang tua mengetahui gejala awal gangguan disleksia. Hal ini dapat dibuktikan berdasarkan gejala dan nilai kepastian yang di inputkan oleh orang tua sehingga hasil konsultasi yang ditampilkan lebih akurat.

2. Aplikasi sistem pakar ini mampu membantu orang tua dalam melakukan diagnosa awal karena sistem memberikan informasi mengenai jenis gangguan disleksia yang diderita oleh anak beserta dengan penanganannya.

3. Aplikasi sistem pakar ini mampu menghemat waktu orang tua karena orang tua tidak perlu mengunjungi dan mengantri ditempat psikolog atau lembaga-lembaga psikologi lainnya. Setelah orang tua mengetahui jenis gangguan disleksia anak dari sitem, maka orang tua hanya perlu melakukan penanganan lanjut ke psikolog atau psikiater.

\section{DAFTAR PUSTAKA}

A.S, Rossa \& Salahuddin, M. 2013. Rekayasa Perangkat Lunak (Terstruktur Dan Berorientasi Objek). Bandung: Informatika.

Desiani, Anita \& Arhami, Muhammad. 2005. Konsep Kecrdasan Buatan. Yogyakarta: ANDI.

Hakim, Lukmanul. 2008. Membongkar Trik Para Master PHP dan MySQL. Yogyakarta: LOKOMEDIA.

Kawuryan Fajar dan Trubus Raharjo. 2012. "Pengaruh Stimulasi Visual Untuk Meningkatkan Kemampuan Membaca Pada Anak Disleksia". Jurnal Psikologi.

Kusrini. 2006. Sistem Pakar, Teori, Dan Aplikasi. Yogyakarta : ANDI OFFSET.

Mandala, Eka Praja Wiyata. 2015. Web Programing Project 1 "e.p.w.m. Forum". Yogyakarta: ANDI.

Rohajawati Siti dan Supriyati Rina. 2010. "Sistem Pakar Diagnosis Penyakit Unggas Dengan Menggunakan Metode Certainty Factor". Jurnal Komputer.

Sadeli, Muhammad. 2013. Toko Baju Online Dengan PHP Dan MySQL. Palembang: Maxicom.

Sutojo, T dkk. 2011. Kecerdasan Buatan. Yogyakarta: ANDI OFFSET.

Suyanto. 2006. Artificial Intelligence. Bandung: Inforrmatika. 